\title{
Новая техника для картофелеводства
}

\section{Н.Н. Колчин, А.Г. Пономарев, В.Н. Зернов}

Представлены новые современные модели машин: универсальный навесной культиватор-гребнеобразователь КГП-4; картофелепосадочная машина CR450M с возможностью совмещения ряда технологических операций (подготовка почвы, посадка, гребнеобразование, опрыскивание, локальное внесение гранулированных удобрений и защита от эрозии); оригинальный комбайн Spirit 5200 бункерного типа; намеченный к серийному производству безбункерный комбайн (копатель-погрузчик) AVR Lynx.

Ключевые слова: картофель, машинные технологии, комплексы машин, культиватор, новые модели, картофелесажалки, комбайны, контроль управления, качество работы.

$\mathrm{H}$ есмотря на неблагоприятные экономические условия в аграрном секторе России, производство картофеля за прошедший период по сравнению с другими с.х. культурами снизилось незначительно. В последнее время ежегодно в нашей стране производят около 30 млн т картофеля, несмотря на то, что практически перестали существовать некогда активно работавшая отрасль сельскохозяйственного машиностроения и система создания и массового производства новой техники. Были ликвидированы многие тракторные и заводы с.- х. машиностроения, специализированные КБ и ГСКБ системы Министерства тракторного и сельскохозяйственного машиностроения. Прекратил существование всемирно известный головной научно-исследовательский институт отечественной отрасли сельхозмашиностроения - ВИСХОМ, успешно создававший современные машины для комплексной механизации работ в сельском хозяйстве страны [1].

На сохранившихся отдельных заводах отрасли сельхозмашиностроения изготавливаются по заявкам потребителей, подчас по устаревшей технической документации, малые серии и единичные образцы машин. Возник недостаточно организованный импорт техники из Германии, Нидерландов, Бельгии, Белоруссии, Польши и других стран без проведения должных ее испытаний и сертификации для условий России [2].

Типаж и параметры специальной техники для производства картофеля, применяемые в разных странах мира, включая Россию, весьма разнообразны. К ним относятся культиваторы разных типов, картофелепосадочные машины, уборочные машины, в т.ч. комбайны, техника для послеуборочной доработки клубней и механизации работ в хранилищах. Широкое и эффективное применение машинных технологий производства картофеля в имеющемся многообразии условий достигается умелым применением комплексов разных типоразмеров требуемой технологической конфигурации [3].

Сегодня ряд российских предприятий совместно с зарубежными партнерами пытаются возродить производство картофельной техники на современном высоком уровне. Так, хорошо зарекомендовали себя в хозяйствах различных субъектов РФ комплексы машин, выпускаемые фирмами Amazone Eurotechnika (Россия, г. Самара), «Колнаг» (Россия, г. Коломна) и рядом белорусских производителей.

Условия производства картофеля в России, платежеспособность производителей данной продукции, доступность банковских кредитов и объемы субсидий; предпола-

\section{Показатель}

Габариты Д×Ш×В, м

Количество обрабатываемых гребней, шт. Высота формируемого гребня, мм Ширина гребня по верхнему основанию, мм Масса эксплуатационная, кг

Производительность основного времени, га/ч

Таблица 1. Основные технические данные культиватора-гребнеобразователя КГП-4

гают, что на обозримую перспективу развитие отрасли картофелеводства преимущественно ориентируется на комплексы машин среднего типоразмера по типу, выпускаемому в настоящее время ООО «Колнаг» в содружестве с фирмой AVR (Бельгия) [4].

Подобные комплексы широко используют в различных почвенно-климатических условиях выращивания картофеля в нашей стране и за сезон обеспечивают его эффективное производство по современным технологиям на площади до 120 га. При помощи специальных опций, приспособлений и сменных узлов машины комплекса можно применять для уборки столовых корнеплодов и лука.

Оригинальная отечественная машина комплекса - универсальный навесной комбинированный культиватор-гребнеобразователь КГП-4 с почвоприводными рабочими органами для подготовки полей к посадке картофеля и уходу за ними (рис. 1). В комплекс специальных машин также включены новые современные машины: две модели четырехрядной прицепной автоматической картофелепосадочной машины CR450M (рис. 2, 3) для междурядий 75 и 90 см и прицепной двухрядный комбайны Spirit 5200 бункерного типа (рис. 4). В перспективе в составе комплекса намечено производство безбункерного комбайна (копателя-погрузчика) AVR Lynx (рис.5). Основные технические данные этих машин представлены в таблицах 1-3.

Картофелепосадочные машины могут быть выполнены в четырехрядном и двухрядном исполнении в прицепном или навесном вариантах с механическим или гидрав-

\begin{tabular}{|c|c|}
\hline \multicolumn{3}{|c|}{ Модель } \\
\hline $4 \times 75$ & $4 \times 90$ \\
\hline $2,3 \times 3,4 \times 1,25$ & $2,3 \times 4,0 \times 1,25$ \\
\hline \multicolumn{3}{|c|}{4} \\
\hline 175 & до 300 \\
\hline \multicolumn{3}{|c|}{850} \\
\hline
\end{tabular}




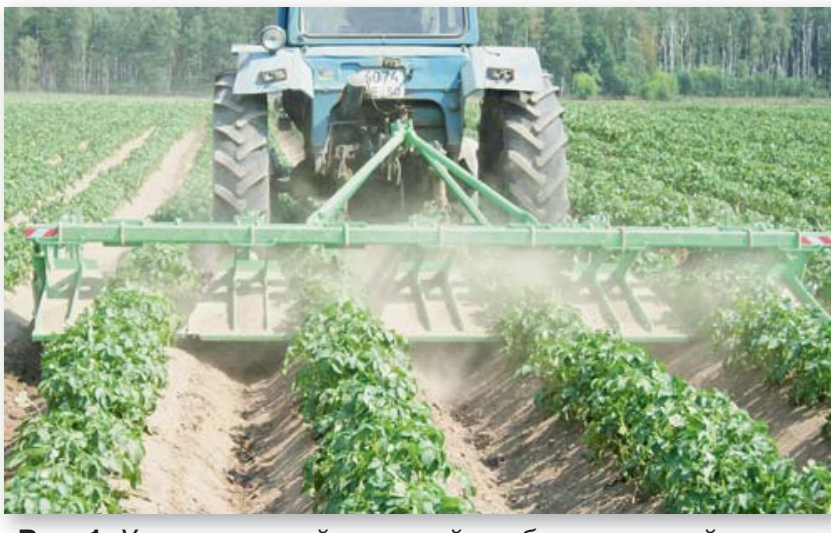

Рис. 1. Универсальный навесной комбинированный культиватор-гребнеобразователь КГП-4 с почвоприводными рабочими органами

лическим приводом высаживающих аппаратов, а также могут использоваться в составе посадочных комплексов с передненавесным культиватором Multivator или культиватором Ge-Force C на специальной навеске с длинным дышлом, либо с портальной транспортной тягой.

Картофелепосадочные машины CR450M могут оснащаться опрыскивающим комплектом и гранулятоты растений и локального внесения удобрений. С целью формирования полнообъемных гребней одноврером для применения средств защи-

менно с посадкой применяют гребнеобразующие плиты. В качестве опции, вместо гребнеобразующей плиты, могут устанавливать бороздообразователи. Еще одной опцией является планчатый каток, монтируемый на бороздообразователь. Катки прижимают гребни, разбивают почвенные комья по их верху и образуют качественно сформированные рядки рыхлой почвы. Чтобы не допустить разрушения почвенного слоя на склонах, картофелепосадочная машина может комплектоваться устройством для защиты от эрозии почв. В процессе посадки между гребнями формируются канавки, которые образуют «бассейны» для накопления воды, не допуская тем самым эрозию почвы. Комплект для защиты от эрозии почв работает от гидравлики трактора. Он представляет собой независимое гидравлическое устройство, не связанное с гидравликой посадочной машины.

Таблица 2. Основные технические данные моделей картофелепосадочной машины CR 450M

\begin{tabular}{|c|c|c|}
\hline \multirow{2}{*}{ Показатель } & \multicolumn{2}{|c|}{ Модель } \\
\hline & $4 \times 75$ & $4 \times 90$ \\
\hline Вместимость бункера, кг & 3500 & 4000 \\
\hline Габариты Д×Ш×В (бункер опущен/поднят), м & $5,4 \times 3,3 \times 2,03 / 2,54$ & $4,0 \times 5,3 \times 2,03 / 2,54$ \\
\hline Ширина междурядий, см & 75 & 90 \\
\hline Шаг посадки клубней, мм & \multicolumn{2}{|c|}{$108-515$} \\
\hline Глубина заделки клубней, мм & \multicolumn{2}{|c|}{$40-180$} \\
\hline Трактор, л. с. (не менее) & \multicolumn{2}{|c|}{90} \\
\hline Производительность, га/ч & \multicolumn{2}{|c|}{ до 2,7} \\
\hline
\end{tabular}

Таблица 3. Основные технические данные комбайнов Spirit 5200 и Lynx

\begin{tabular}{|c|c|c|}
\hline \multirow{2}{*}{ Показатель } & \multicolumn{2}{|c|}{ Модель } \\
\hline & AVR Spirit 5200 & AVR Lynx \\
\hline Общая масса, кг & 8500 & 8500 \\
\hline $\begin{array}{l}\text { Количество сепарирующих } \\
\text { транспортеров, шт. }\end{array}$ & 6 & $\begin{array}{c}\text { Различное в модифика- } \\
\text { циях }\end{array}$ \\
\hline $\begin{array}{l}\text { Шаг прутков полотен сепарирующих } \\
\text { транспортеров, мм }\end{array}$ & $40 / 50$ & $35 / 40 / 43 / 50$ \\
\hline $\begin{array}{l}\text { Ширина рабочей зоны сепарирующих } \\
\text { транспортеров, мм }\end{array}$ & \multicolumn{2}{|c|}{1650} \\
\hline Вместимость бункера, кг & до 6000 & нет \\
\hline Максимальная высота выгрузки, м & 4,2 & 4,0 \\
\hline Габариты Д×Ш×В, м & $10,41 \times 3,30 \times 3,80$ & $12,70 \times 3,30 \times 3,99$ \\
\hline Мощность трактора (не менее), л.с. & 90 & 140 \\
\hline
\end{tabular}

Таким образом, за один проход агрегата при необходимости можно выполнять от одной до шести операций - подготовку почвы, посадку, гребнеобразование, опрыскивание клубней либо почвы (ложе для клубней), локальное внесение гранулированных удобрений и защита почв от эрозии.

В случае использования комбинации устройства для внесения удобрений и культиватора Ge-Force C для подготовки почвы, навешиваемого на картофелепосадочную машину, применяется только портальная транспортная тяга.

Ведущими зарубежными фирмами все больше опрыскивателей выпускается со стандартной увеличенной шириной шин опорных колес и рабочего захвата с целью минимизации нежелательных последствий воздействия на почву. Чтобы пройти между картофельными гребнями, необходимо наличие достаточного пространства. Для организации такого пространства на сажалке предусмотрен комплект формирования колеи опрыскивания. Возникает необходимость через определенное количество проходов сажалки разравнивания двух гребней вместо посадки в них клубней. Эти два разравненных гребня и представляют колеи для опрыскивателя. Такая опция увязана с опцией электрического отключения первого и четвертого высаживающих аппаратов картофелесажалки. В зависимости от модели, система может управляться с блока управления, либо с джойстика в кабине трактора.

Картофелепосадочные машины серии CR450M совмещают точность раскладки клубней в рядке известных чашечных высаживающих аппаратов с высокой производительностью. При этом комплект сменных чашек приспособлен для различных сортов клубней, различающихся по форме и массе.

Диаметр верхнего шкива высаживающего аппарата имеет большой диаметр, гарантирующий надежную передачу клубней с лицевой стороны чашек на тыльную. На нижнем шкиве малого диаметра происходит быстрое раскрытие чашек, что обеспечивает требуемую точность раскладки клубней в борозде на высокой скорости посадочного агрегата. В сочетании с загрузочным бункером посадочной машины большой емкости это обеспечивает повышение производительности на посадке.

Механический встряхиватель ленты высаживающего аппарата на- 
страивается в зависимости от размерно-массовых характеристик высаживаемых клубней. В стандартной комплектации посадочная машина оборудована встряхивателями, работающими от электропривода, интенсивность которых регулируется с помощью потенциометра из кабины трактора.

Спереди каждого высаживающего аппарата посадочной машины установлен сошник, закрепленный на сошниковой балке с параллелограммной подвеской и двумя колесами контроля глубины посадки. Сошник имеет сменную носовую часть, выполненную из износостойкого материала. За носовой частью установлен металлический штифт, обеспечивающий рыхлый слой почвы под клубнем.

При работе машины возможно использование функций GPS управления. Стандартный режим GPS в тракторе поможет настроить прямолинейное движение и линии границ участка. Чтобы пользоваться функциями «Precision farming» (точная посадка) и «section control» (контроль участка), на экране должна быть активирована опция GPS. C помощью GPS «Section control» можно управлять функциями включения (отключения) высаживающих аппаратов и соответствующих встряхивателей и секций опрыскивания, а также комплекта для формирования колеи для прохода колес опрыскивателя (разравнивателя гребней).

Модельный ряд картофелеуборочных комбайнов AVR Spirit, в ceмействе которых находится однорядный комбайн модели Spirit 6100 (бункер на 6000 кг), двухрядный комбайн модели Spirit 6200 (с таким же бункером) и двухрядный комбайн модели Spirit 9200 (с бункером на 9000 кг), пополнился оригинальным двухрядным прицепным комбайном Spirit 5200 (бункер до 6000 кг).

Картофелеуборочный комбайн Spirit 5200 отличает новая система просеивающих, ботвоотделяющих, сепарирующих и подающих транспортеров с горизонтальным сортировочным столом, обеспечивающая равномерный поток картофеля и высокое качество отделения почвы и ботвы с минимальными механическими повреждениями клубней.

Первичная сепарация на комбайне производится длинным подкапывающим транспортером, а ботва удаляется посредством решетного транспортера. Полотно решетного транспортера для ботвы имеет две скорости движения относительно просевающего транспортера (88 или 70\%), его высота над просевающим транспортером регулируется с инспекционного стола.

Площадки у переборочного стола достаточны для размещения четырех человек. Бункер с двойным подъемом вмещает 6000 кг, оснащен выгрузным элеватором с противоударным покрытием на планках, высота выгрузки до 4,0 м. Предусмотрена автоматическая система направления машины на подкапываемые рядки. Наряду с пультом управления технологическим процессом работы комбайна в кабине трактора, имеется дополнительный пульт управления сепарирующими рабочими органами непосредственно с переборочного стола комбайна, что повышает его технологическую гибкость.

К а р то фел е уборочный комбайн Spirit 5200 обеспечивает высокое качество получаемого продукта. Наличие опции «Мягкий спуск» позволяет производить затаривание клубней в контейнеры прямо из бункера. Автопилот «диаболо», роторная гребенка отделения примесей, автомат наполнения бункера и другие «умные» функции исключают влияние человеческого фактора на качество уборки.

На намеченном к постановке на производство в 2019 году копателе-погрузчике AVR Lynx предусмотрена развитая система сепарирующих рабочих органов. Она включает стандартные прутковые полотна, выносную горку с пальчатым полотном, батарею поперечных сепарирующих роликов, регулируемый прутковый элеватор Varioweb и транспортер для подачи убранного картофеля в рядом идущее транспортное средство. Привод сепарирующих рабочих органов полностью гидравлический. Узлы гидравлической и электрической систем комбайна вынесены на одну боковую сторону его рамы, что 


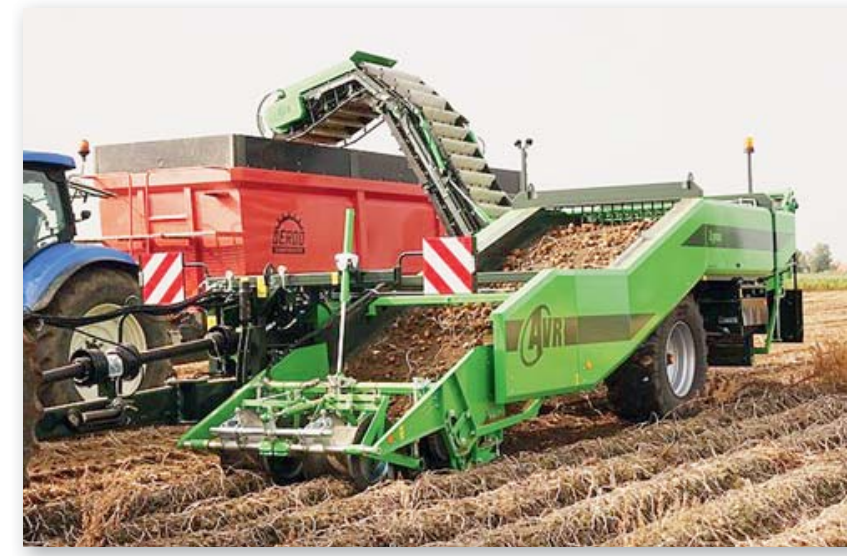

Рис. 5. Комбайн картофелеуборочный AVR Lynx
Федеральное государственное бюджетное научное учреждение «Федеральный научный агроинженерный центр ВИМ (ФГБНУ ФНАЦ ВИМ). E-mail: kolchinnn@ mail.ru.

Пономарев Андрей Григорьевич, канд. техн. наук, в.н.с. Федеральное государственное бюджетное научное учреждение «Федеральный научный агроинженерный центр ВИМ (ФГБНУ ФНАЦ ВИМ).

существенно облегчает обслуживание машины. Отмечается хорошая обзорность из кабины трактора всех рабочих органов комбайна при его работе.

Дышло комбайна легко переводится гидроцилиндром в положение бокового подкопа, что позволяет работать с трактором на широкой рези не колес. Точное ведение подкапывающей части комбайна по гребню осуществляется автоматически, повышая эргономику контроля и управления комбайном.

Будущее сельского хозяйства России - в преимущественном и эффективном использовании современной техники, в том числе на основе цифровых технологий, как реального средства обеспечения продовольственной безопасности страны и конкурентоспособности российского продовольствия на внутреннем и мировом рынках $[3,5]$.

\section{Библиографический список}

1.Колчин Н.Н., Елизаров В.П., Михеев В.В., Пономарев А.Г. Современные технологии и техника для подготовки семенного материала. Картофель и овощи. 2014. № 5. C. $27-29$.

2.Колчин Н.Н., Зволинский В.Н. И вновь о деле чрезвычайной государственной важности // Тракторы и сельхозмашины. 2017. № 8. С. 13-16.

З.Туболев С.С., Колчин Н.Н. Развитие отечественного сельскохозяйственного машиностроения на примере производства специальной техники для картофелеводства и овощеводства. М. ФГБНУ «Росинформагротех", 2011. С.68.

4.Колчин Н.Н., Зернов В.Н., Петухов С.Н., Аксёнов А.Г. Применение и развитие машинных технологий производства картофеля // В сб.: «Картофелеводство: Материалы научно-практической конференции». Под ред.С.В. Жеворы. 2017. С. 89-97.

5.Зернов В.Н., Петухов С.Н. Перспективы разви тия отечественной сельскохозяйственной техники // Инновации в сельском хозяйстве. 2018. № 4 (29). С. 285-293.

\section{Об авторах}

Колчин Николай Николаевич, доктор техн. наук, профессор, г.н.с.,

\section{E-mail: agrodisel@mail.ru.}

Зернов Виталий Николаевич, канд техн. наук, в.н.с., Федеральное государственное бюджетное научное учреждение «Федеральный научный агроинженерный центр ВИМ (ФГБНУ ФНАЦ ВИМ). E-mail: vim@vim.ru

New machinery for potato growing N.N. Kolchin, DSc, prof., chief research fellow, Federal State Budgetary Scientific Institution «Federal Scientific Agroengineering Center VIM» (FSBSI FSAC VIM).E-mail:kolchinnn@mail.ru

A.G. Ponomarev, PhD, leading research fellow, FSBSI FSAC VIM.

E-mail: agrodise/@mail.ru

V.N. Zernov, PhD, leading research fellow, FSBSI FSAC VIM. E-mail: vim@vim.ru

Summary. Modern and reliable machinery and innovative machine technologies for potato production are key factors in improving potato production efficiency. The current conditions of potato production in Russia show that medium-sized complexes are the most popular and widespread today. A number of Russian enterprises together with foreign partners are trying to revive the production of potato equipment in our country of medium size at a new level. The article presents new modern models of machines universal mounted cultivator-comb-forming cultivator KGP-4; potato-planting machine CR450M with the possibility of combining a number of technological operations (soil preparation, planting, combing, spraying, local application of granular fertilizers and protection against soil erosion); original combine Spirit 5200 bunker type; scheduled for mass production without a bin harvester (digger- loader) AVR Lynx.

Keywords: potato production, machine technologies, complexes of machines, cultivator, models of new machines, potatoplanting machines, combines, control management, quality of work.
Аграрии Бурятии занялись семенным

\section{производством картофеля}

В 2019 году ООО «Гарантия-2» вошло в реестр семеноводческих хозяйств. На его ухоженной земле овощеводы высаживают 450 га сортового картофеля.

Картофель, морковь, свекла, капуста - вот основные культуры, выращиваемые на Прибайкальской земле. Посевная площадь по сравнению с 2018 годом увеличена на 155 га, в том числе на 15 га под капустой, на 10 га под свеклой и на 130 га под картофелем.

Старший агроном «Гарантия-2» Иван Кузнецов рассказывает: «Вкусовые качества отличные, особенно сорт хорош для жарки и запекания, поэтому пользуется большим спросом у огородников. Норма высадки - 54 тыс. клубней на га. Будем закладывать семенные участки».

В этом году в хозяйстве усилена команда агрономов. Так, Иван Кузнецов вместе с семьей переехал в Бурятию из Иркутской области. Теперь старший агроном надеется попасть в программу «Устойчивое развитие сельских территорий» и построить собственный дом в Кабанском районе. Ведь именно здесь «Гарантия-2» займется семенным направлением, так как в 2019 году фермеры вошли в единый реестр семеноводческих хозяйств и получили сертификат соответствия. Теперь на территории бывшего хозяйства «Бин-Агро» будет заложено 45 га под семенной картофель. Первая партия элитного посадочного материала сорта Розара уже поступила в хозяйство.

Очевидный плюс заключается и в том, что мелиоративные работы сегодня Минсельхозпрод Бурятии субсидирует в размере 50\%. Получив статус семеноводческого хозяйства, ООО «Гарантия-2» может претендовать на дополнительные меры господдержки, в том числе на компенсацию 30 \% приобретения минеральных удобрений и средств химической защиты растений.

Источник: www.advis.ru 